\title{
Hypopigmentation and subcutaneous fat atrophy associated with corticosteroid injection: a case report
}

\author{
Fata Prihatsari ${ }^{1} \bowtie$, Hanik Badriyah Hidayati ${ }^{1}$, Damayanti Damayanti ${ }^{2} \bowtie$, \\ Trianggoro Budisulistyo ${ }^{3}$
}

Author affiliations:

\begin{abstract}
1. Campus A, Faculty of Medicine, Universitas Airlangga. Mayjen. Prof. Dr. Moestopo Street, No. 47, Surabaya, Indonesia. \{ORCID:0000-0002-2517-9188\}

2. Campus A, Faculty of Medicine, Universitas Airlangga. Mayjen Prof. Dr. Moestopo Street, No. 47, Surabaya, Indonesia. \{ORCID:0000-0002-6825-1311\}

3. Department of Dermatology and Venereology, Faculty of Medicine, Universitas Airlangga, Surabaya, Indonesia. \{ORCID:0000-0003-2388-6740\}

4. Department of Neurology, Medical Faculty, Universitas Diponegoro, Semarang, Indonesia.
\end{abstract}

Correspondence: Hanik Badriyah Hidayati; E-mail: hanikhidayati@yahoo.com; Phone: +6282131035699

\section{Abstract}

Corticosteroid injections have been shown to be an effective treatment modality in many of the musculoskeletal and rheumatologic conditions. Yet, the potential adverse effects of corticosteroid injections have not been given much attention. One of the potential adverse effects that should be considered by clinicians is skin hypopigmentation and subcutaneous fat atrophy. Although it is a rare side effect, it may have cosmetically unpleasant effect. The aim of this case report is to highlight the importance of providing adequate information to the patients regarding these dermal adverse effects of corticosteroid injections. We report the case of a 31-year-old female who suffered from skin hypopigmentation and subcutaneous fat atrophy after triamcinolone injection given for de Quervain's tenosynovitis.

Key words: de Quervain's tenosynovitis; Fat atrophy; Hypopigmentation; Corticosteroid injections; Adverse effects; Pain

Citation: Prihatsari F, Hidayati HB, Damayanti D, Budisulistyo T. Hypopigmentation and subcutaneous fat atrophy associated with corticosteroid injection: a case report. Anaesth. pain intensive care 2021;25(6):807-811; DOI:

10.35975/apic.v25i6.1708

\section{Introduction}

De Quervain's tenosynovitis is the most common overuse injury of the wrist resulting from repetitive microtrauma and shearing of the first dorsal compartment tendons. ${ }^{1}$ The condition was first described by de Quervain, a Swiss surgeon, in $1895 .^{2}$ The prevalence of de Quervain's tenosynovitis is reported in $1.3 \%$ of women and $0.5 \%$ of men. ${ }^{3}$ Initially, it is managed conservatively using oral nonsteroidal anti-inflammatory drugs (NSAIDs), immobilization, diathermy, splinting, massage, and corticosteroid injection. Operative treatment is reserved for cases in which conservative therapy has failed. Corticosteroid injection is more favorable than other non-surgical treatments and has the highest treatment success rate compared with oral NSAID, splinting, or combination therapy. ${ }^{4,5}$ A variety of corticosteroid formulations have the success rate of $62 \%$ to $93 \% .^{6}$

Pain is a common symptom of de Quervain's tenosynovitis. ${ }^{7}$ Pain is defined by the International Association for the Study of Pain as "an unpleasant sensory and emotional experience associated with actual or potential tissue damage, or described in terms of such damage. $" 8,9,10$ The aim of pain management is to improve the quality of life of the patients by relieving pain and helping them to gain proper functioning. ${ }^{11}$ Unrelieved 
and long-standing pain may substantially affect psychological well-being. ${ }^{12}$ Corticosteroid injections are frequently administered to treat pain associated with rheumatic and musculoskeletal disorders and have been registered as a localized treatment of varying conditions, such as rheumatoid arthritis, tendinopathy, bursitis, synovitis, epicondylitis, ganglion condition, neuromas, fasciitis, back pain, and entrapment syndrome. ${ }^{13}$ The possible sites of local corticosteroid injections include tendon sheath, bursas, enthesis, intraarticular space, soft tissue, and epidural space. ${ }^{14}$ In spite of common use in practice, adverse effects associated with corticosteroid injections are not adequately appreciated. We report a case of hypopigmentation and subcutaneous fat atrophy associated with corticosteroids.

\section{Case Report}

A 31-year-old right-handed Asian female presented with a 2 weeks' history of pain in her right wrist. The pain traveled up her forearm and was substantially aggravated with movement. She reported a Numeric Rating Scale (NRS) score of approximately 5-7 (on an 11-point scale). There was no history of prior trauma. Her earlier medical history was noncontributory. On examination, there were swelling and tenderness on the lateral aspect of her right hand. The Finkelstein test result was positive. Therefore, a clinical diagnosis of de Quervain's tenosynovitis was made. She was initially treated conservatively with NSAIDs. After 10 days of this treatment without significant improvement, she subsequently had a single local corticosteroid injection. She received a mixture of $1 \mathrm{~mL}$ triamcinolone acetonide $10 \mathrm{mg} / \mathrm{mL}$ and $1 \mathrm{~mL}$ of $1 \%$ lidocaine hydrochloride. Injection was performed using a $26 \mathrm{G}$ needle, advanced at an angle of $45^{\circ}$ toward the peritendinous sheath of the first dorsal compartment. The procedure was uneventful. She was also placed in a thumb spica orthosis. No infection was noted after the injection. Post-injection NRS was 3-4 after 2 weeks, and the pain resolved completely after 3 weeks. A month following the injection, she noticed a depressed, hypopigmented area around the needle insertion site on her brown-toned skin. The lesion measured $1 \times 1.6 \mathrm{~cm}$. Neither motor nor sensory impairment was present on her follow-up examination. One and a half years later, her hypopigmented skin and subcutaneous fat atrophy resolved gradually without any specific treatment.

\section{Discussion}

Corticosteroid injections are a well-established treatment modality in alleviating symptoms of de Quervain's tenosynovitis. ${ }^{15}$ These are increasingly being used for other musculoskeletal and rheumatic conditions. ${ }^{13}$ Yet, the adverse effects of corticosteroid injections have not been given much attention. Direct corticosteroid injections to the lesion site may avoid many of the

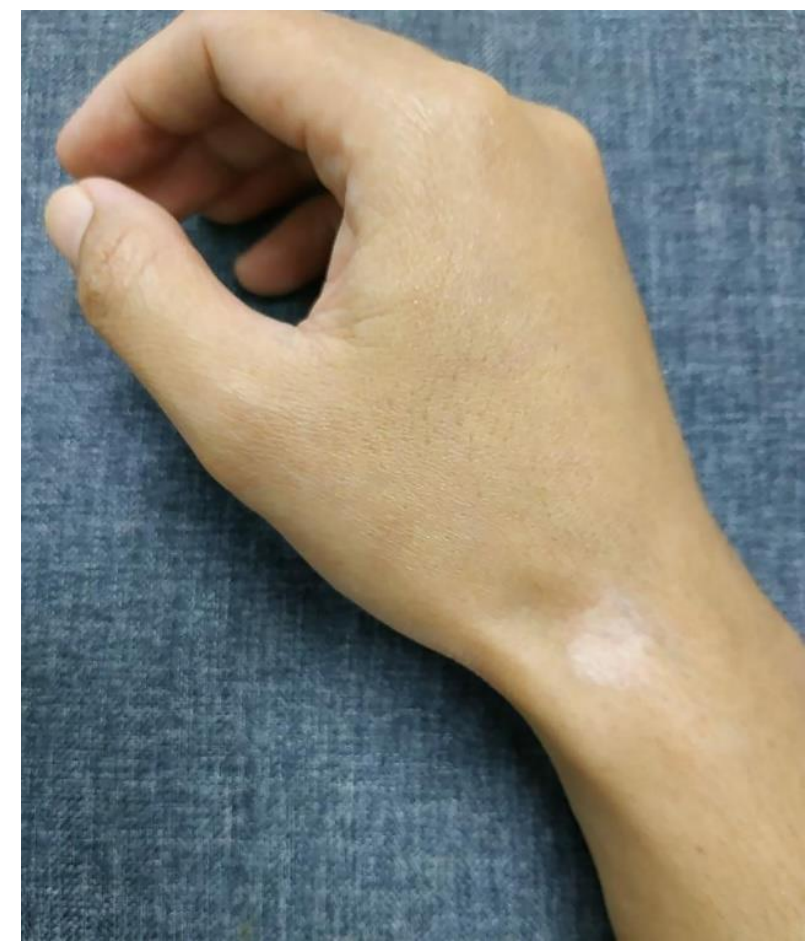

Figure 1: Skin hypopigmentation and subcutaneous fat atrophy associated with corticosteroid injection around the injection site

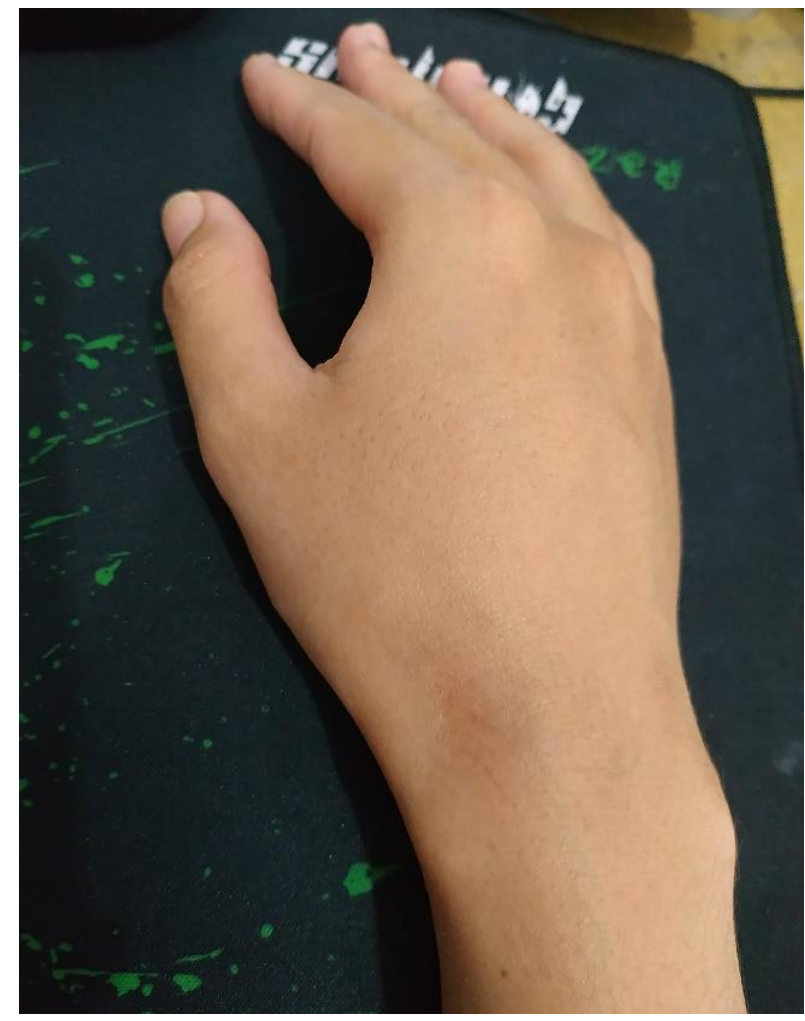

Figure 2: Resolved skin hypopigmentation and subcutaneous fat atrophy one and a half years later 
potential adverse effects associated with corticosteroid systemic administration, such as suppression of hypothalamus-pituitary-adrenal axis, endocrine changes, and growth inhibition. ${ }^{16}$ Possible major adverse effects of local corticosteroid injections ranged from minor to major manifestations. Major adverse effects include tendon ruptures, necrotizing fasciitis, severe subcutaneous fat atrophy, osteomyelitis, and skin hypopigmentation. Minor adverse effects that could occur include disturbance in menstruation, steroid flare, milder soft tissue alteration, and skin rash. ${ }^{17}$

Frequently used corticosteroids are methylprednisolone, triamcinolone, dexamethasone, and betamethasone. Each preparation differs in potency, cost, and corticosteroid related reactions, and the duration of action. ${ }^{14}$ The solubility of a preparation has an inverse relationship with the duration of action. The more soluble a preparation, the shorter the duration of action the preparation has, because it is absorbed from the joint faster. ${ }^{17}$ Triamcinolone acetonide is one of the corticosteroids approved by Food and Drugs Administration (FDA) for injection. ${ }^{18}$ Triamcinolone acetonide is the least soluble steroid; hence, it has a longer duration of action. ${ }^{17}$ This is the reason why majority of the clinicians prefer to use this compound. ${ }^{19}$ However, less soluble steroids may have more deleterious effects on adjacent soft tissues. ${ }^{14,17}$ The size of the affected area and the length of time of such dermal adverse effects are possibly influenced by the concentration and solubility of the corticosteroid preparation. ${ }^{20}$

The incidence of skin hypopigmentation has been reported to range from $1.3 \%$ to $4 \%$, whereas subcutaneous fat atrophy has been found to range from $1.5 \%$ to $40 \%$ in five studies. ${ }^{13}$ Although the incidence of hypopigmentation associated with corticosteroid injection was considered to be low, it could be bothersome for the patient once it appears. Moreover, a recent review by Pace et al. found that the incidence of the soft tissue adverse effects associated with corticosteroid injection in the management of de Quervain's tenosynovitis and tennis elbow is reportedly as high as $31 \%$ and up to $40 \%$, respectively. Patients with darker skin tone have a greater risk of developing a noticeable hypopigmentation. ${ }^{17,21,22}$

According to other case reports, hypopigmentation may develop 1-4 months later, following single or multiple injections. $^{23,24}$ This is similar to our experience. Our patient developed skin hypopigmentation and subcutaneous fat atrophy 3 months after a single injection with triamcinolone acetonide and resolved spontaneously within one and a half years. However, late manifestation of up to 10 months has also been reported. It then resolves after 6-30 months in the majority of cases. A few cases may be irreversible. ${ }^{17,23}$
There is no specific treatment for hypopigmentation. ${ }^{23}$ Application of vitamin E paste and exposure of narrow ultraviolet rays for half a year were used to treat hypopigmentation in the study by $\mathrm{Gu}$ et al. However, this treatment yielded a slow regression (82.50\%) or consistent result $(17.50 \%)$ in a year of follow-up duration. ${ }^{25}$ Fat grafting, serial normal saline infiltration, and temporal fascia implantation are a few of the treatment options that may be considered with regard to refractory subcutaneous fat atrophy. ${ }^{23}$

Subcutaneous fat atrophy and skin hypopigmentation associated with triamcinolone injection have been reported to affect several injection sites, depending on the location of the injection. Dhawan et al. reported such dermal adverse effect after intralesional injection in two patients for ganglion over the wrist and a patient for lichen planus on the foot. ${ }^{24}$ Salvatierra et al. described such a lesion after triamcinolone injection for a tennis elbow. ${ }^{19}$ Another researcher reported an atrophic and hypopigmented lesion in the postauricular region following multiple intralesional triamcinolone acetonide for the treatment of a keloid on the left ear. ${ }^{26}$ Another report of such a lesion was made after intralesional injection on the eyelid of a 2-year-old girl with chalazion. $^{27}$

The pathophysiology of subcutaneous fat atrophy and skin hypopigmentation associated with corticosteroid injection has not been clearly elucidated. A histopathological study by $\mathrm{Gu}$ et al. revealed that the number of melanocytes was not affected in corticosteroid-induced hypopigmentation. However, their function was impaired. This might be caused by inhibition of prostaglandin or cytokine production in epidermal cells and suppression of a secretory metabolic product from melanocytes. ${ }^{16,25}$ Concerning subcutaneous fat atrophy, it has been suggested that the corticosteroids have antiproliferative effects on keratinocytes and fibroblasts. It is also known that corticosteroid alters the metabolism of extracellular matrix proteins and the synthesis of lipids in the skin. ${ }^{28}$ The adipocytes were reduced in number and size, and, in some cases lipophages, which are macrophages engulfing adipose tissue, appeared. ${ }^{29}$

There are some precautions that can minimize the risk of subcutaneous fat atrophy and skin hypopigmentation. The needle should be changed after drawing up the corticosteroid preparation, and local anesthetic is subsequently used to dilute it. ${ }^{30}$ Moreover, applying pressure using a sterile dressing at the injection site while the needle is withdrawn could avoid leakage of corticosteroid preparation into the subcutaneous tissue. ${ }^{21}$ Superficially injecting corticosteroid may also cause leakage along the needle track and subsequently put the injection site at risk. ${ }^{14}$ 
The type of injected corticosteroid may also contribute to the risk of developing subcutaneous fat atrophy and skin hypopigmentation. Compared to methylprednisolone, the risk of dermal changes is higher with triamcinolone injection because of its increased crystal size. Accordingly, triamcinolone acetonide is preferably injected into deep soft tissue targets or large joints. ${ }^{14}$ Injecting triamcinolone $40 \mathrm{mg} / \mathrm{mL}$ carries a substantially higher risk compared with injecting $10 \mathrm{mg} / \mathrm{mL} .^{25}$ Dexamethasone and soluble betamethasone can be considered to be a more appropriate option when subcutaneous fat atrophy and skin hypopigmentation are the issues to be concerned. ${ }^{17}$

Ultrasonography guidance is commonly used in musculoskeletal pain management. ${ }^{31}$ However, Milani et al. reported a case of skin hypopigmentation and atrophy following ultrasonography-guided triamcinolone injection for de Quervain's tenosynovitis; this may suggest that these dermal adverse effects could still occur even under imaging guidance. ${ }^{28}$ This finding is corroborated by a prospective study conducted by Shin YH et al., which compared ultrasonography-guided and blind triamcinolone injection for de Quervain's tenosynovitis and demonstrated that both groups were not significantly different in the incidence of subcutaneous fat atrophy or skin hypopigmentation. ${ }^{32}$ In fact, even when all preventive measures have been taken, adverse effects may still occur.

\section{Conclusion}

This report presents subcutaneous fat atrophy and skin hypopigmentation as an uncommon dermal adverse effect that may occur following corticosteroid injection. It is prudent to initially provide patients with adequate information about these dermal adverse effects before performing the procedure, particularly in case of darkskinned patients. Although the condition may resolve spontaneously without any specific treatment, it should not be ignored. Some patients may find it bothersome and may lose confidence because of its cosmetically unpleasant effect. Ultimately, clinicians should promptly recognize it as an adverse effect associated with corticosteroid injection.

\section{Conflict of Interest}

The authors have no conflict of interest to disclose

\section{Acknowledgment}

This study did not receive a specific grant from any funding agency in the public, commercial, or not-forprofit sectors.

\section{Authors' Contribution}

FP: writing the initial draft
$\mathrm{HBH}$ : Revising it critically for important intellectual content, final approval of the version to be published

DT: contributed to the writing of the manuscript

TA: provided critical feedback to the writing of the manuscript

\section{References}

1. Llopis E, Restrepo R, Kassarjian A, Cerezal L. Overuse injuries of the wrist. Radiol Clin North Am. 2019 Sep;57(5):957976 [PubMed] DOI:10.1016/j.rcl.2019.05.001

2. Ahuja NK, Chung KC. Fritz de Quervain, MD (1868-1940): Stenosing tendovaginitis at the radial styloid process. J Hand Surg Am. 2004 Nov;29(6):1164-1170 [PubMed] DOI: 10.1016/j.jhsa.2004.05.019

3. Abi-Rafeh J, Kazan R, Safran T, Thibaudeau S. Conservative management of de quervain stenosing tenosynovitis: review and presentation of treatment algorithm. Plast Reconstr Surg. 2020 Jul;146(1):105-126 [PubMed] DOl: $10.1097 /$ prs.0000000000006901

4. Mardani-Kivi M, Mobarakeh M K, Bahrami F, HashemiMotlagh K, Saheb-Ekhtiari K, Akhoondzadeh N. Corticosteroid injection with or without thumb spica cast for de Quervain tenosynovitis. J Hand Surg Am. 2014 Jan;39(1):37-41 [PubMed] DOI: 10.1016/j.jhsa.2013.10.013

5. Stephens MB, Beutler Al, O'Connor FG. Musculoskeletal injections: a review of the evidence. Am Fam Physician. 2008 Oct;78(8):971-976 [PubMed] [Free Full Text]

6. Ilyas AM. Nonsurgical treatment for de Quervain's tenosynovitis. J Hand Surg Am. 2009 May-Jun;34(5):928-9. [PubMed] DOI: 10.1016/j.jhsa.2008.12.030

7. Huisstede BM, Gladdines S, Randsdorp MS, Koes BW. Effectiveness of conservative, surgical, and postsurgical interventions for trigger finger, dupuytren disease, and de Quervain disease: a systematic review. Arch Phys Med Rehabil. 2018 Aug;99(8):1635-1649.e21 [PubMed] DOI: 10.1016/j.apmr.2017.07.014

8. Hidayati HB, Pranata CA. Pathogenesis and management of pain in amyotrophic lateral sclerosis. Anaesth pain intensive care. $2021 \quad$ Apr;25(2):236-243[Free Full Text] DOI:10.35975/apic.v25i2.1478

9. Hidayati HB, Kustriyani A. Paracetamol, migraine, and medication overuse headache (MOH). JPHV. 2020 Sep;1(2):42-47 [Free $\quad$ Full Text] DOI:10.21776/ub.jphv.2020.001.02.5

10. Hidayati HB, Sugianto P, Khotib J, Ardianto C, Kuntoro, Machfoed $\mathrm{MH}$. Behavioral assesment of the peripheral neuropathic pain model: rat with $\mathrm{CCl}$ (chronic constriction injury). Neurona. 2018 Jun;35(3):209 [Free Full Text]

11. Rachmawati $Y$, Hidayati $H B$. The role of substance $p$ in chronic low back pain (CLBP). J Islamic Pharm. 2019;4(2):914 [Free Full Text] DOI: 10.18860/jip.v4i2.8163

12. Topcu SY. Relations among pain, pain beliefs, and psychological well-being in patients with chronic pain. Pain Manag Nurs. 2018 Dec;19(6):637-644 [PubMed] DOI: 10.1016/j.pmn.2018.07.007 
13. Brinks A, Koes BW, Volkers ACW, Verhaar JAN, BiermaZeinstra SMA. Adverse effects of extra-articular corticosteroid injections: a systematic review. BMC Musculoskelet Disord. 2010 Sep;11(1):206 [PubMed] [Free Full Text] DOI: 10.1186/1471-2474-11-206.

14. Shah A, Mak D, Davies AM, James SL, Botchu R. Musculoskeletal corticosteroid administration: current concepts. Can Assoc Radiol J. 2019 Feb;70(1):29-33 [PubMed] [Free Full Text] DOI: 10.1016/j.carj.2018.11.002.

15. Rowland P, Phelan N, Gardiner S, Linton KN, Galvin R. The effectiveness of corticosteroid injection for de Quervain' $s$ stenosing tenosynovitis (DQST): a systematic review and meta-analysis. Open Orthop J. 2015 Sep;9:437-44 [PubMed] [Free Full Text] .

16. Jang WS, Park J, Yoo KH, Han TY, Li K, Seo SJ, et al. Branchshaped cutaneous hypopig- mentation and atrophy after intralesional triamcinolone injection. Ann Dermatol. 2011 Feb;23(1):111-114 [PubMed] [Free Full Text] DOI:10.5021/ad.2011.23.1.111.

17. Pace CS, Blanchet NP, Isaacs JE. Soft tissue atrophy related to corticosteroid injection: review of the literature and implications for hand surgeons. J Hand Surg Am. 2018 Jun; 43(6):558-563 [PubMed] DOI: 10.1016/j.jhsa.2018.03.004.

18. Setianti AR, Hidayati HB. Effectiveness of triamcinolone and lidocaine in patient with piriformis syndrome - a case series. Pharmaceutical Journal of Indonesia. 2019;5(1):31-35 [Free Full Text]

19. Salvatierra ARA, Alweis R. Permanent hypopigmentation after triamcinolone injection for tennis elbow. J Community Hosp Intern Med Perspect. 2016 Jul;6(3):31814. [PubMed] [Free Full Text] DOI: 10.3402/jchimp.v6.31814 .

20. MacMahon PJ, Eustace SJ, Kavanagh EC. Injectable corticosteroid and local anesthetic preparations: a review for radiologists. Radiology. 2009 Sep;252(3):647-661[PubMed] [Free Full Text].

21. Papadopoulos PJ, Edison JD. The clinical picture - soft tissue atrophy after corticosteroid injection. Cleve Clin J Med. 2009 Jun;76(6):373-374 [PubMed] [Free Full Text] .

22. Liang J, McElroy K. Hypopigmentation after triamcinolone injection for de quervain tenosynovitis. Am J Phys Med Rehabil. 2013 Jul;92(7):639 [PubMed] [Free Full Text] DOI: 10.1097/phm.0b013e318269ebdc
23. Martins N, Polido-Pereira J, Caneira M, Fonseca JE. Treatment of persistent cutaneous atrophy after corticosteroid injection with fat graft. Reumatol Clin. 2019 Nov-Dec;15(6): e122-e124 [PubMed] [Free Full Text] DOI: 10.1016/j.reuma.2017.09.002

24. Dhawan AK, Bisherwal K, Grover C, Tanveer N. Linear leucoderma following intralesional steroid: a report of three cases. J Cutan Aesthet Surg. 2015 Apr-Jun;8(2): 117-119 [PubMed] [Free Full Text] DOI: 10.4103/0974-2077.158453

25. Gu AK, Zhang XJ, Liu XP, Kong XJ, Zhang LT. Reflectance confocal microscopy and histological features of depigmentation after local corticosteroid injection. Skin Res Technol. 2019 Nov;25(6):835-838 [PubMed] DOI: 10.1111/srt.12730

26. Doong JC, Chapman LW, Smith J. Hypopigmentation on the ear. Cutis. 2018 Jul;102(1):E19-E20 [PubMed] [Free Full Text]

27. Park J, Chang M. Eyelid fat atrophy and depigmentation after an intralesional injection of triamcinolone acetonide to treat chalazion. J Craniofac Surg. 2017 May; 28(3):e198-199 [PubMed] DOI: 10.1097/SCS.0000000000003367

28. Milani C, Lin C. Proximal linear extension of skin hypopigmentation after ultrasound-guided corticosteroid injection for de Quervain tenosynovitis: a case presentation. PM\&R. 2018 Aug;10(8):873-876 [PubMed] DOl: 10.1016/j.pmrj.2018.01.001

29. Margulies S, Morris A. Successful treatment of lipoatrophy with normal saline. JAAD Case Rep. 2015 Nov;1(6): 415-417 [PubMed] [Free Full Text] DOI: 10.1016/j.jdcr.2015.10.008

30. Pekarek B, Osher L, Buck S, Bowen M. Intra-articular corticosteroid injections: a critical literature review with up-todate findings. Foot. 2011 Jun;21(2):66-70 [PubMed] DOI: 10.1016/j.foot.2010.12.001

31. Hidayati HB. Ultrasound and management strategies in chronic pain. Anaesth pain intensive care. 2020;24(6):579-81 DOI:10.35975/apic.v24i6.1393

32. Shin YH, Choi SW, Kim JK. Prospective randomized comparison of ultrasonography-guided and blind corticosteroid injection for de Quervain's disease. Orthop Traumatol Surg Res. 2020 Apr;106(2):301-306 [PubMed] [Free Full Text] DOI: 10.1016/j.otsr.2019.11.015 